- RAM, REV. ADM. MACKENZIE, 15(6), Edição Especial • SÃO PAULO, SP • NOV./DEZ. 2014 • ISSN 1518-6776 (impresso) • ISSN 1678-6971 (on-line) • http://dx.doi.org/10.1590/1678-69712014/administracao.v15n6p98-121. Submissão: 18 ago. 2014. Aceitação: 3 nov. 2014.

Sistema de avaliação: às cegas dupla (double blind review). UNIVERSIDADE PRESBITERIANA MACKENZIE.

Ana Silvia Rocha Ipiranga, Eloisio Moulin de Souza e Maria Luisa Mendes Teixeira (Ed. Convidados), p. 98-121.

\title{
1 ALBERTO GUERREIRO RAMOS: \\ CONTRIBUIÇÕES DA REDUÇÃO \\ SOCIOLÓGICA PARA O CAMPO CIENTÍFICO \\ DA ADMINISTRAÇÃO PÚBLICA NO BRASIL
}

\author{
MAURO GUILHERME MAIDANA CAPELAR \\ Doutorando em Administração da Faculdade de Economia, Administração e Contabilidade \\ da Universidade de Brasília (Face-UnB). \\ SQN 316, Bloco K, ap. 230, Asa Norte, Brasília - DF - Brasil - CEP 70775-110 \\ E-mail: capelari.unb@gmail.com

\section{YEDDA BEATRIZ GOMES DE ALMEIDA DYSMAN \\ DA CRUZ SEIXAS SINGER AFONSO}

Mestranda em Administração da Faculdade de Economia, Administração e Contabilidade da Universidade de Brasília (Face-UnB).

SEPN 515, Conjunto D, Lote 4, Asa Norte, Brasília - DF - Brasil - CEP 70770-504

E-mail: beatrizsinger@gmail.com

\section{ANDRÉAA DE OLIVEIRA GONÇALVES}

Doutora em Integração da América Latina pelo Programa de Pós-Graduação Integração da América Latina da Universidade de São Paulo (USP).

Coordenadora do Programa de Pós-Graduação em Gestão Pública da Universidade de Brasília (UnB). Área Universitária 1, Nossa Senhora de Fátima, Planaltina - DF - Brasil - CEP 73345-010

E-mail: andreagon@unb.br 


\section{RESUMO}

O ensaio teórico apresenta a proposta de Alberto Guerreiro Ramos sobre redução sociológica, na dimensão de método histórico e atitude parentética, como sugestão de tema aos estudos sobre o campo científico da administração pública no Brasil. Procuramos dialogar com duas questões: "De que modo podemos desenvolver um entendimento mais sistemático da administração pública nacional?" e "O que precisamos (re)conhecer para que o campo da administração pública nacional seja mais responsivo, correspondendo melhor aos anseios públicos locais?". Seguindo Guerreiro Ramos, sugerimos que o campo estudado lance mão do uso metodológico da história e da ação parentético-substantiva. O primeiro diz respeito à assimilação crítica da produção intelectual estrangeira que permitiria a uma comunidade não se servir exclusivamente de experiências de outras comunidades na realização de seu projeto histórico. O segundo está relacionado com um posicionamento lúcido e ativo dos seres humanos em relação aos fatores que os condicionam, permitindo um ajustamento ativo deles na sociedade e, sobretudo, nas organizações econômicas. Eis as sugestões propostas por este trabalho: reavivar a necessidade de os pesquisadores brasileiros utilizarem conhecimento e produções científicas estrangeiras de maneira subsidiária, uma vez que há intenção primeira de atender às necessidades de uma realidade que, em muitos pontos, se apresenta de modo distinto das realidades em que as teorias/modelos surgiram; e fomentar a visão parentético-substantiva dos indivíduos para a construção de modelos de organização que, embora não excluam, façam com que modelos econômicos organizacionais dividam espaços com modelos mais voltados a garantir qualidade de vida, autorrealização, interação social primária, satisfações sociais e participação na produção de bens públicos.

\section{PALAVRAS-CHAVE}

Guerreiro Ramos. Redução sociológica. Campo científico. Administração pública. Brasil. 


\section{INTRODUÇÃO}

A administração pública, pensada sobre as bases de campo científico (Bourdieu, 2004; Ortiz, I983), tem sido recorrentemente discutida no Brasil (Pacheco, 2003; Fadul \& Silva, 2009; Peci, Ribeiro, Rodrigues, \& Fornazin, 20II) e em outros países (Kettl, 2000; Bogason \& Brans, 2008; Orozco, 2009; Raadschelders \& Lee, 20II). Em especial no Brasil, essa discussão busca alertar para uma importante passagem que inclui dois fatores que, muitas vezes, se comportam de forma dicotômica: o aumento da produção científica na área de administração pública tanto em eventos quanto em periódicos nacionais e os pequenos e isolados números de cursos de graduação e pós-graduação e de grupos de pesquisas consolidados em administração pública no país. Nesse sentido, não causa estranheza o fato de os trabalhos produzidos se limitarem a descrever episódios e eventos ocorridos, não se dedicarem a explicar os fenômenos sociais, utilizarem como estratégia metodológica única o estudo de caso e focarem casos convergentes da agenda governamental momentânea e, em menor intensidade, dos anseios do público. Demonstram, com isso, um campo sem identidade, que produz conhecimento descontínuo e com baixa capacidade de devolver o conhecimento produzido para a sociedade.

O debate que se faz presente, portanto, é a necessidade de apresentar a proposta de Alberto Guerreiro Ramos sobre redução sociológica, na dimensão de método histórico e atitude parentética, como sugestão de tema aos estudos sobre o campo científico da administração pública no Brasil. Entendemos por campo a categoria analítica que busca enfatizar a existência de um espaço social em que "estão inseridos os agentes e as instituições que produzem, reproduzem ou difundem [...] a ciência” (Bourdieu, 2004, p. 20). Essas sugestões poderiam ajudar no avanço científico da própria administração pública, direcionando as construções do campo para caminhos híbridos que contemplem tanto a eficiência organizacional como, e principalmente, formas mais participativas de produção do bem público. Além do mais, sugestões ao campo tendem a contribuir com trabalhos que busquem, em primeira instância, o atendimento das necessidades sociais e a construção de organizações mais inclusivas em um Brasil que é marcado historicamente pela desigualdade social, pelo patrimonialismo e pelo coronelismo (Faoro, 200I; Carvalho, I997).

Refletindo essa conjuntura apresentada para o campo da administração pública nacional, este trabalho pretende dialogar com as seguintes questões:

- De que modo podemos desenvolver um entendimento mais sistemático da administração pública nacional? 
- O que precisamos (re)conhecer para que o campo da administração pública nacional seja mais responsivo, correspondendo melhor aos anseios públicos locais?

Como eixo norteador, defendemos a ideia de que novos temas de pesquisa no campo da administração pública nacional devem perpassar pelo uso metodológico da história, conforme aponta Guerreiro Ramos (1965), considerando a importante e obrigatória aproximação dos pesquisadores ao contexto da realidade brasileira, o que pode potencializar, dessa forma, uma posição de engajamento e compromisso consciente com a realidade social local. Em acréscimo, defendemos ainda que a administração pública nacional deve considerar a racionalidade noética ou substantiva, nos moldes de Guerreiro Ramos (I972), uma vez que há necessidade de os "homens" se posicionarem de forma parentética para construir instituições mais inclusivas e que atendam fundamentalmente às necessidades sociais. Em vias de fato, portanto, pretendemos expor a proposta metodológica e parentética de redução sociológica elaborada por Guerreiro Ramos (I972, p. 54) e a contribuição dela para "habilitar o estudioso a praticar a transposição de conhecimentos e de experiências de uma perspectiva para outra", sobretudo com a finalidade de sugerir tais temas ao campo da administração pública brasileira, nosso principal objetivo.

O artigo está dividido em três seções, além desta introdução e das considerações finais. Na próxima seção, abordar-se-ão aspectos referentes ao campo da administração pública no Brasil. A seguir, descreve-se e analisa-se a redução sociológica, sobretudo no que tange ao seu sentido histórico e de atitude parentética. Por fim, apresentam-se a redução sociológica e suas principais contribuições para o campo científico da administração pública brasileira.

\section{ADMINIStraçÃo pÚBLICA NO BRASIL: UM CAMPO EM CONSTRUÇÃO}

O conceito de campo, proposto por Bourdieu (2004, p. 20), está ligado ao universo em que se inserem os agentes e as instituições que produzem, reproduzem e difundem a arte, a literatura ou a ciência. A estrutura de um campo é delimitada, em parte, pelos agentes que definem suas possibilidades e impossibilidades, o conjunto dominante de seus objetivos e questões que importam ou não para suas pesquisas. Desse modo, o campo é demarcado pela estrutura de seu capital científico. Além disso, um campo científico não é estático, pois sua estrutura e seus agentes estão em constante movimento e envolvidos em embates 
tanto pela conquista da representação quanto da realidade do referido campo. Para este trabalho, entendemos a administração pública como um campo científico em constante construção e os pesquisadores, que se dedicam a estudar a administração pública, como agentes não passivos dentro desse campo. Portanto, apresentar as principais características do campo da administração pública nacional, objetivo desta seção, contribuirá para melhor enxergarmos as possibilidades da redução sociológica em cooperar com os estudos do campo em análise.

A administração pública mundial, e no Brasil em particular, vem em constante processo de crescimento quantitativo de sua produção acadêmica. Para perceber essa tendência (Peci et al., 20II), basta observar a quantidade de submissão de artigos aos principais eventos da área - Encontro da Associação Nacional de Pós-Graduação e Pesquisa em Administração (EnAnpad) e Encontro de Administração Pública da Anpad (EnAPG) - e a proliferação de revistas especializadas e de cursos de graduação e pós-graduação no país. Muito embora esse crescimento seja positivo e demonstre, de forma parcial, que a administração pública vem ganhando espaço nos meios acadêmicos, problemas no campo não são incomuns tampouco recentes. Os primeiros trabalhos revisores da área de administração pública, no Brasil, datados da década de I980, já mostravam inconsistências importantes no campo.

Machado-da-Silva, Amboni e Cunha (1989), por exemplo, demonstraram que há fragilidades especialmente no que tange ao baixo uso da literatura estrangeira e à preponderância de metodologias pouco aprofundadas e de trabalhos prescritivos com baixa capacidade analítica e voltados para análises práticas e menos teórico-empíricas. Como sugestões para a superação das fragilidades do campo, esses autores apontam: analisar o desenvolvimento da administração pública de forma híbrida, com temáticas tanto de políticas públicas como de análises organizacionais, e/ou concentrar o campo em temas significativos para a administração pública, como sistema político e sua efetividade, agências públicas e sua representatividade, e sistema administrativo público e sua legitimidade.

Em trabalho desenvolvido com o objetivo de responder à questão "O que é administração pública no Brasil?”, Keinert (I998) apresentou, até aquele momento, a evolução do campo da administração pública no Brasil (I937-1997). Para a autora, a presença da dicotomia "política-administração" não permitiu a definição clara do local institucional - locus - e de perspectivas teóricas - focus - do campo. Ao revisar longitudinalmente os exemplares da Revista de Administração Pública (RAP) e da Revista do Serviço Público (RSP), Keinert (I998) percebeu o deslocamento inicial do conceito de "público" nos trabalhos, em que esse termo deixa de ser compreendido como uma entidade estatal e passa a ser interpretado como uma representação do interesse público. Tal constatação é percebida pela modificação nas características dos trabalhos publicados que vinham, com 
maior frequência, não mais se restringindo a estudos do aparelho do Estado e da burocracia governamental, mas buscando incorporar temas que envolviam uma gama maior de atores nas discussões de questões públicas atrelados a perspectivas político-organizacionais (Keinert, I998).

Em suas conclusões, Keinert (1998) sugere que existe um movimento na administração pública brasileira, embora ele ainda não chegasse a substituir o paradigma prevalecente, que vem incluindo temas de pesquisa a partir da compreensão de "público" como espaços e interesses sociais/públicos. Tais temas começam, portanto, a abordar questões como: papel do Estado, democratização, gestão participativa, movimentos sociais e terceiro setor; visão integradora, holística e intersetorial; gerenciamento de conflitos e interesses divergentes; descentralização; qualidade na prestação do serviço público; inovação; ensino e pesquisa em administração pública; novos tipos de demanda gerencial (terceiro setor e conselho administrativo); e controle social direto.

Em revisão mais recente do campo, Pacheco (2003), ao buscar a maior pertinência e qualidade das publicações da área, aponta algumas características do campo da administração pública presentes nas publicações da RAP e da RSP do EnAnpad entre I995 e 2002. As características encontradas para o campo foram as seguintes: predominância de padrões normativos nas pesquisas; interlocutores restritos aos próprios pares e temáticas pouco transversais; heterogeneidade temática; estudo de caso como abordagem metodológica tônica, setorial e sem preocupação nas comparações; pesquisadores do campo divididos entre a pesquisa e a consultoria; riscos de assimilação acrítica de conceitos e teorias desenvolvidas em outras disciplinas. Pacheco (2003) não reivindica a autonomia da área, mas sugere a exposição da administração pública em campos mais estruturados, principalmente por meio da valorização dos trabalhos publicados em outras áreas, como a Associação Nacional de Pós-Graduação e Pesquisa em Ciências Sociais (Anpocs) e revistas de ciência política. Sugere, ainda, o deslocamento do campo da administração pública da área "administração e turismo" para áreas próximas da ciência política e das políticas públicas na avaliação da Coordenação de Aperfeiçoamento de Pessoal de Nível Superior (Capes), a centralidade na formação de reformadores públicos e a sedimentação do campo via predeterminação de temáticas a serem pesquisadas.

Apesar da presença, portanto, de inúmeros problemas e também sugestões para o campo da administração pública no Brasil, o que pretendemos neste ensaio é colaborar, mesmo que minimamente, para a inserção da redução sociológica como possível tema de pesquisa no campo da administração pública no Brasil, a partir da compreensão de público como uma instituição voltada aos interesses e às demandas da sociedade. Colaborar com formas de pensar as organizações públicas a partir das propostas de redução sociológica de Guerreiro Ramos seria 
resgatar, aos nossos olhos, demandas de aproximação entre a área da administração e áreas com campos mais consolidados, como de ciências sociais, incitadas por Pacheco (2003). Mas também seria colaborar para a ampliação de novos espaços públicos e a sedimentação de um campo que se apresenta ainda de maneira tímida e limitada para a sociedade brasileira, qual seja: o público como de interesse público na produção e na implementação das políticas.

\section{REDUÇÃO SOCIOLÓGICA: O MÉTOdO HISTÓRICO E A ATITUdE PARENTÉTICA}

A construção dos significados da expressão redução sociológica por Alberto Guerreiro Ramos foi realizada de modo fragmentado e em diferentes épocas. Três foram os principais sentidos desenvolvidos ao longo de seus estudos que, de forma complementar, deram corpo ao que veio a ser apresentado como redução sociológica em seu modo mais acabado no livro A nova ciência das organizações (Guerreiro Ramos, I98I). Eis os três sentidos da expressão redução sociológica apresentados pelo autor: I. método histórico que estimula a realização de um trabalho dotado de valor pragmático e de concepções e fatos sociais locais, 2. atitude parentética e 3. proposta de uma nova ciência social. Especificamente, este trabalho considera os dois primeiros sentidos propostos para a redução sociológica.

Para Guerreiro Ramos (1965), redução tem o sentido de eliminar todo o excesso que perturba a compreensão e a obtenção do que é essencial em um dado. A eliminação ocorre em toda a forma secundária e acessória de informação que não permite que a ideia seja apreciada em seu formato original e tampouco que sua essência seja contemplada. Assim:

No domínio restrito da sociologia, a redução é uma atitude metódica que tem por fim descobrir os pressupostos referenciais, de natureza histórica, dos objetivos e fatos da realidade social. A redução sociológica, porém, é ditada não somente pelo imperativo de conhecer, mas também pela necessidade social de uma comunidade que, na realização de seu projeto de existência histórica, tem de servir-se da experiência de outras comunidades (Guerreiro Ramos, 1965, p. 82).

Embasado nessa definição, a redução sociológica se assenta em sete pressupostos:

- Atitude metódica, compreendida como o esforço de, por meio de regras, depurar objetos de elementos que perturbem a percepção dos seus significados. 
- Não admitir a existência, na realidade social, de objetos sem pressupostos, o que alude à necessidade de conhecer os fatos da realidade social, uma vez que formam um conjunto coerente de partes necessárias e com vínculos de significação.

- Noção de mundo que denota a reciprocidade entre consciência e perspectiva observada. Noção de mundo, portanto, é a percepção da consciência de cada pessoa em relação ao objeto observado, o que garante percepções diferentes dos objetos para cada pessoa que o observa, a depender da consciência de cada indivíduo.

- Perspectiva, significado que o autor constrói para esclarecer que cada objeto observado é constituído, também, por meio da perspectiva em que este se insere, o que expressa que a transferência de um objeto de uma perspectiva para outra modifica sua essência.

- Os suportes da redução sociológica são coletivos e não individuais, ou seja, não estariam presentes na consciência do pesquisador ou do sujeito individual, mas apresentar-se-iam como instrumento do saber operativo e da lógica material, caracterizando-se como imanente à sociedade.

- Procedimento crítico-assimilativo da experiência estrangeira que vai de encontro às expectativas dos que transplantam literalmente produtos culturais importados. Guerreiro Ramos (1965), entretanto, alerta que a redução sociológica não se caracteriza como um romantismo exacerbado do local ou do regional, mas individualiza-se como um método dirigido por uma inspiração universal e mediatizada por influências locais e regionais.

- Atitude altamente elaborada, no sentido de colocar à mostra pressupostos de natureza histórico-social dos objetos em análise, já que a pesquisa dos objetos só se efetiva pela sistematização e pelo rigoroso raciocínio acerca das razões nas quais se fundamenta (Guerreiro Ramos, I965).

De modo a corroborar os pressupostos anteriormente descritos, Guerreiro Ramos (I965) defende o compromisso redutor, normatizando-o metodologicamente em quatro leis. A primeira é nomeada de lei do comprometimento, ou seja, é a adoção sistemática de uma posição de engajamento e também de compromisso consciente com o contexto local. Aqui é demonstrado que a noção de mundo de um pesquisador não é constituída exclusivamente, tampouco em primeira instância, de esforço intelectivo, mas é de esforço não intelectual e da perspectiva existencial do próprio cientista. Assim, o pesquisador estaria condicionado por um a priori existencial, isto é, por sua experiência com objetos/ pessoas do mundo particular em que viveu e por seu contexto histórico-social, quer ele tenha consciência ou não desse condicionamento. A segunda lei é a do caráter subsidiário da produção científica estrangeira. De acordo com essa lei, 
os objetos em análise podem ser considerados, no domínio da sociologia, sob diversas formas (noemas), como é o caso da palavra "Estado", que tem diferentes interpretações, dependendo do país estudado. Dessa maneira, não se mostra adequado o fato de consumir in natura a produção estrangeira, uma vez que ela foi embasada com um tipo ideal de Estado que se enquadra com a realidade daquela região e que talvez não se tenha o mesmo tipo ideal de Estado para ser replicado em outro país, no caso, o Brasil. O que carece ser realizado, segundo Guerreiro Ramos (1965), é utilizar a produção estrangeira como matéria-prima, sempre condicionada por fatores particulares da sociedade local, isto é, de forma subsidiária (cf. Azevêdo, 2006).

A terceira lei diz respeito à universalidade dos enunciados gerais da ciência. Para Guerreiro Ramos (I965), a ciência é universal em dois sentidos: I. todos aqueles que se devotam a ela se apresentam, na maioria das vezes, convergidos com as mesmas características semânticas, ou seja, admitem válidos os mesmos enunciados centrais da ciência; e 2. o mundo não está compartimentado, e, por isso, os povos estão estreitamente relacionados uns com os outros, o que permite que avanços obtidos em um país alastrem-se para outros países rapidamente. Nesse sentido, a redução sociológica não nega a universalidade da ciência, todavia demanda do pesquisador submeter o trabalho científico à exigência da comunidade em que vive. A quarta e última lei relaciona-se com a "fase" em que a sociedade se encontra e com a explicação dos problemas de uma sociedade estar em função dessa fase. Isto é, nenhum fenômeno social pode ser compreendido em sua totalidade se não estiver embasado em uma fase histórico-social para fins de pertinência e de transcendência explicativa dos problemas sociais. Assim, a quarta lei concerne à impossibilidade de compreender os fatos sem referi-los à realidade (fase), à vida ou à história em que se acham integrados.

A título de ilustração do que chamou de redução sociológica, Guerreiro Ramos (I965) apresenta o conceito de "controle social" e mostra a importância dele para a sociologia norte-americana e sua baixa estimação para os estudos sociais no Brasil. Conforme apontou o autor, "controle social" assume relevância na sociologia norte-americana em decorrência do caráter problemático da integração nacional nos Estados Unidos. Nesse país, foram aplicadas técnicas de manipulação indireta de conduta, acrescidas de práticas de coação, muito em razão do desejo de fortalecimento da estabilidade social. Em todo o mundo, foi nos Estados Unidos que a coletividade avançou em maior grau em termos de evolução econômico-social, o que ocasionou problemas na transferência da experiência coletiva de uma geração para outra, fato que tornou indispensáveis os estudos sobre "controle social" a partir da análise da formação histórica desse país. No Brasil, embora o conceito de "controle social", conforme desenvolvido nos Estados Unidos, seja aplicável, ele não teria a relevância encontrada naquele 
país dada a fase histórica em que o Brasil se encontrava. O fato é que, por aqui, a temática de maior interesse para a sociedade estaria no estudo da dicotomia entre estagnação e desenvolvimento, representada por classes sociais com interesses conflitantes, e, portanto, os estudos sobre "controle social" se apresentariam como secundários para aquele momento. Além disso, uma adoção literal pelos pesquisadores nacionais em relação ao conceito e aos estudos sobre "controle social", nos moldes norte-americanos, geraria distorções para o interesse da coletividade nacional. Isso ocorreria porque "controle social" para os norte-americanos "supõe o interesse em anular as tensões, conservando a estrutura já estabelecida, e a solução dos antagonismos fundamentais da atual sociedade brasileira requer antes a mudança na qualidade de sua estrutura" (Guerreiro Ramos, I965, p. 89).

$\mathrm{Na}$ linha condutora em defesa da redução sociológica como um método de assimilação crítico da produção sociológica estrangeira, Guerreiro Ramos (I957) elabora o livro Introdução crítica à sociologia brasileira, no qual apresenta suas divergências intelectuais e seus julgamentos negativos aos principais nomes da sociologia e antropologia brasileira da época, como Florestan Fernandes, Darci Ribeiro, Costa Pinto, Arthur Ramos, Roger Bastide, entre outros. Sua postura de ajuizamento esteve calcada na propositura entendida como síndrome da alienação do pensamento sociológico acadêmico brasileiro.

Essa síndrome apresentou-se, segundo o sociólogo, sobre as bases de seis características, todas elas imbricadas entre si:

- Simetria e sincretismo: representam a apropriação, mimética, dos intelectuais brasileiros às obras desenvolvidas em outros centros urbanos, principalmente norte-americanos e europeus. Tal simetria fazia com que boa parte dos estudos desenvolvidos no contexto nacional estivesse dogmaticamente embasada em conhecimentos "alienígenas" ou estrangeiros e, ainda, sem passar por uma revisão crítica que evidenciasse a real aplicabilidade desses conhecimentos à realidade brasileira.

- Dogmatismo: referenciou a postura da apologia e da submissão dos cientistas sociais do Brasil, que adotavam e generalizavam, nas falas ou na montagem mecanizada de escritos, proposituras de cientistas renomados no campo sociológico.

- Dedutivismo: entendido como a tomada de propostas estrangeiras como sendo verdades absolutas e, portanto, se caracterizando como o ponto de partida para a elaboração, compreensão e explicação da vida social brasileira, sem levar em consideração as peculiaridades da formação histórica nacional.

- Alienação: vista como fruto da percepção contemplativa dos cientistas, fato que impossibilitava a autodeterminação dos estudos sociais brasileiros e a preocupação com o desenvolvimento do país. 
- Inautenticidade: encontrada na não presença, nos trabalhos do pesquisador social brasileiro, da pura experiência cognitiva do próprio pesquisador (Guerreiro Ramos, I957; Azevêdo, 2006).

A possibilidade para o aparecimento de um pensamento autenticamente nacional no Brasil, segundo Guerreiro Ramos (I965), foi a tomada de consciência crítica por uma parcela da sociedade brasileira. Assumir traços coletivos, de consciência libertária e autônoma, de personalização e da compreensão dos condicionamentos humanos locais é característica intrínseca desse formato crítico de consciência. Além disso, essa consciência seria capaz de conduzir os "homens" à percepção e compreensão dos fatos que os determinam e distingui-los da matéria bruta ou de uma "coisa". Dessa forma, o próprio "homem" torna-se agente de transformação e construção social, ao mesmo tempo que se constitui historicamente, isto é, o "homem" se configura como um ente reflexivo posicionando-se como sujeito perante certos determinantes exteriores ao mesmo tempo que se livra da consciência ingênua e do formalismo, entendidos como puro objeto de determinantes. Um plano existencial autoconsciente e autodeterminado, portanto, conceberia uma modalidade superior da existência humana em que os condicionantes humanos passariam a ser mais bem compreendidos. Essa modalidade seria o desfecho proporcionado pela consciência crítica (Guerreiro Ramos, I996).

Segundo o sociólogo, existiria uma urgente necessidade de os "homens" se posicionarem de um modo lúcido e ativo em relação aos fatores que os condicionavam. Tal posicionamento, amparado pela consciência crítica, adicionaria aos seres humanos uma atitude que ainda não lhes era presente: a atitude parentética. Como definição, Guerreiro Ramos (I972, p. 243) sugeria a atitude parentética como a "capacidade psicológica do indivíduo de separar-se de suas circunstâncias internas e externas", proporcionando, assim, uma compreensão do eu e de sua vivência dentro do mundo. De fato, a atitude parentética traria aos seres humanos poder sobre si mesmos e sobre as circunstâncias externas, promovendo seu ajustamento ativo na sociedade e, sobretudo, nas organizações econômicas. O papel central da atitude parentética, portanto, seria proporcionar a emancipação humana no mundo, assim como incentivar o surgimento de novas propostas de organização e de sistemas sociais que estivessem mais próximos de atender às necessidades de realização dos seres humanos.

Vale destacar, rapidamente, que Guerreiro Ramos possuía convicções intelectuais distintas de Emile Durkheim, especialmente no que tange aos estudos antropológicos dos seres humanos dentro das ciências sociais. Em busca de uma crítica à maneira como as ciências sociais entendiam e tratavam os "homens" (ideologia disfarçada), Guerreiro Ramos (I970) elabora o seguinte questionamento: Até que 
ponto as ciências sociais estariam contribuindo para destacar o homem como um ser autônomo?. Para o sociólogo, as ciências sociais tratavam o ser humano por meio do conceito durkheimiano de "homem" normal, ajustado, totalmente socializável, e da convicção de que o ser humano saudável é o não confrontador e o perfeitamente ajustado ao meio social em que vive. Para Guerreiro Ramos (I970), entretanto, não existia somente uma via única em que o "homem" se fazia totalmente moldado por termos e instituições sociais, mas também uma via em que ele poderia avaliar e moldar o meio social conforme as necessidades de cumprimento de suas potencialidades. Assim:

Quando Durkheim e os sociólogos naturalistas preconizam a coação social e admitem que a sociedade forma o homem, é que lhes falta o senso da pessoa, não conhecem a revelação, consideram os homens como indivíduos. Se assim fosse, se o homem procedesse, na sociedade, como indivíduo, somente, não deixaria de assistir certa razão a Durkheim, mas, é preciso levar em conta a força an-arquica especificadora da pessoa, a luta do princípio ontológico original e do princípio normativo social. Não se pode estudar o homem com o mesmo método positivo das ciências. Não se devem considerar os fatos sociais como coisas porque o homem, agindo, procura sempre realizar-se através dos meios sociais (Guerreiro Ramos, I939, pp. 69-70).

A construção do modelo antropológico de homem parentético proposto pelo sociólogo esteve alicerçada no exercício da racionalidade noética ou substantiva. Guerreiro Ramos, embasado nos estudos de Eric Voegelin, admite que a construção de uma boa sociedade está em função do predomínio da razão noética em detrimento da razão pragmática como força criadora da vida humana e, consequentemente, social. Para Guerreiro Ramos, a racionalidade noética tem como objetivo o próprio ser, a sua inteligência, a busca pela liberdade e pela qualidade da pessoa/social. Por sua vez, a razão pragmática é compreendida como a degradação da noética em que predomina o indivíduo e não a pessoa, assim como a visão utilitária e a busca pelo lucro. A racionalidade noética orienta-se por meio de duas dimensões: a individual, que faz menção à autorrealização, compreendida como concretização de potencialidades e satisfação individual; e a de grupo, que diz respeito ao entendimento nas direções das responsabilidades e satisfações sociais. Guerreiro Ramos alega, dessa forma, que o homem parentético é provido de racionalidade noética e que, por isso, assume o papel de um ator político e social, contribuindo para a melhoria da qualidade de vida política e da expansão da liberdade sua e da sociedade em que se insere (Azevêdo, 2006).

Os elementos que compõem a racionalidade noética seriam: I. entendimento, isto é, ações pelas quais se estabelecem acordos e consensos racionais, mediadas 
pela comunicação livre e que coordenam atividades comuns com a intenção de proporcionar responsabilidade e satisfação social; 2. julgamento ético, ou seja, deliberações baseadas em juízos de valor - bom, mau, verdadeiro, falso etc. -, que se realiza por meio do debate racional sobre as pretensões de validez emitidas pelos indivíduos em suas interações; 3. autenticidade, que visa à integridade, honestidade e franqueza dos indivíduos nas interações; 4. valores emancipatórios que apontem para os valores de mudança e aperfeiçoamento do social na direção do bem-estar coletivo, da solidariedade, do respeito à individualidade, da liberdade e do comprometimento presentes nos indivíduos e na conjuntura normativa do grupo; 5. autonomia, que privilegia a condição de os indivíduos agirem e se expressarem livremente nas interações; 6 . autorrealização, entendida como o processo de concretização do potencial inato do indivíduo, assim como de sua vontade presidida por reflexão, pensamento, escolha, decisão e manifestação de sua moralidade individual (Serva, I997, p. 22).

Tendo como base a racionalidade noética, o homem parentético se posicionaria em constante conflito com as organizações econômicas e políticas. Isso decorre do entendimento de que as organizações eram uma ameaça devotada aos valores que os homens portavam, como desenvolvimento humano, promoção da consciência individual e emancipação humana. Além disso, no entendimento de Guerreiro Ramos, as organizações estavam orientadas pelas leis do mercado e pelo egocentrismo. Logo, o tipo parentético de "homem" buscaria equilibrar as relações entre indivíduos e organizações, estas últimas detentoras de características que cerceavam as subjetividades e o sentido daqueles. A recorrente procura e a manutenção da racionalidade noética facilitariam, desse modo, a criação de modelos estruturais mais flexíveis e adaptáveis às exigências dos "homens". Facilitariam ainda a promulgação de demandas, requerimentos e necessidades sociais que precisariam ser respondidos pelos sistemas organizacionais econômicos e políticos. De toda forma, os conflitos com as organizações seriam constantes.

Grosso modo, portanto, a proposta de Guerreiro Ramos (I965) com relação à redução sociológica pretendia mostrar que a construção sociológica de teorias, e no nosso caso de um campo para a administração pública nacional, é mais bem posicionada pela sua funcionalidade em relação à realidade local. Muito embora o autor compreenda que a importação de teorias estranhas às localidades regionais seja algo corriqueiro até mesmo em países mais desenvolvidos cientificamente e, portanto, não descarte essa possibilidade, Guerreiro Ramos (I965) compreende que as teorias dos países subdesenvolvidos deixam de ser teorias atrasadas na medida em que se orientam no sentido de enfocar as regras do contexto histórico-social na qual estão integradas, lançando mão, para isso, da racionalidade substantiva. 


\section{A REDUÇÃO SOCIOLÓGICA E SUAS CONTRIB̉UIÇÕES PARA A CONSTRUÇÃO DO CAMPO CIENTÍFICO DA ADMINISTRAÇÃO PÚBLICA NO BRASIL}

A reflexão, neste trabalho, está assentada na construção do campo científico da administração pública brasileira. Para tanto, propuseram-se as seguintes perguntas: "De que modo podemos desenvolver um entendimento mais sistemático da administração pública nacional?" e "O que precisamos (re)conhecer para que o campo da administração pública nacional seja mais responsivo, correspondendo melhor aos anseios públicos locais?”. Tendo em vista essa conjectura, optamos por introduzir na reflexão conceitos de Guerreiro Ramos, especialmente os que ajudam a construir a proposta de redução sociológica. Dessa maneira, a primeira questão será discutida por meio do uso conceitual do método histórico que incite a construção de um campo dotado de valor pragmático e de concepções e fatos locais; enquanto a segunda questão estará embasada na proposta de indivíduo parentético como forma de pensar novos formatos organizacionais que avancem em modelos mais participativos de produção do bem público.

Duas inquietações, a título de exemplo, ilustram aspectos que não permitem a compreensão sistemática de uma administração pública nacional. A primeira delas é o constante uso e a aplicação de modelos de análise de políticas públicas que, sem exceções, foram constituídos e pensados para atender às necessidades, aos anseios e aos padrões institucionais e políticos distintos, em grande medida, do que é encontrado na realidade política brasileira. Um desses modelos, largamente replicado no Brasil, é o Advocacy Coalition Framework (ACF). Esse modelo procura compreender a formulação e os padrões de mudanças nas políticas públicas numa perspectiva de uma década ou mais. Em complemento ao tradicional "triângulo de ferro", que ressalva exclusivamente as comissões legislativas, as agências oficiais e os líderes de grupos de interesses como os mais relevantes participantes políticos, o ACF expande a área de importância para acadêmicos, jornalistas, funcionários judiciais e agentes de variados níveis de governo, desde que se tornem atores especializados e, portanto, influentes na formulação e implementação da política. O modelo busca, assim, demonstrar como as coalizões ou grupos concorrentes competem por políticas vencedoras dentro de um subsistema político (Weible, Sabatier, \& McQueen, 2009).

Nos estudos que utilizam o ACF como modelo principal de análise de formulação de políticas públicas, a crítica que recorrentemente acompanha o modelo é relativa ao seu caráter descritivo e pouco explicativo. Para além dessa crítica, 
alguns autores europeus e também brasileiros vêm mostrando que a unidade de análise do ACF, ou seja, o subsistema de políticas públicas, não é a unidade mais representativa para estudar determinados processos políticos, uma vez que muitas das decisões de formulação podem vir a ocorrer fora do subsistema em análise ou ainda as participações dos agentes podem ocorrer transversalmente a diferentes estruturas institucionais de tomada de decisão. Um caso emblemático ocorrido no Brasil recente foi a implementação da Lei Florestal n. I2.651/20I2 que, muito embora tenha sido aprovada, seu processo de aprovação foi constituído ainda em um momento em que não havia um consenso dentro do subsistema formal de política ambiental, o que denota que sua aprovação foi realizada mediante subsistemas políticos paralelos. Para a análise da determinada Lei Florestal, dessa forma, o ACF mostrou-se com baixa capacidade de análise e compreensão de um processo político envolto, entre outras características próprias, por relações históricas de distribuição e concentração de terras.

A segunda inquietação está relacionada à falta de conhecimento histórico e social da realidade brasileira nos cursos de formação de carreiras da gestão pública federal, em especial para especialistas em políticas públicas e gestão governamental (EPPGG), coordenados pela Escola Nacional de Administração Pública (Enap). Com a intenção inicial de formar profissionais inter e multidisciplinares com visão abrangente, sistêmica e integrada dos problemas da administração pública, o curso, que sofreu diversas alterações ao longo de sua existência, ainda não contempla especificidades como (Ferrarezi \& Silva, 20I4, p. 76):

- Estímulo à reflexão e ao uso de informação e conhecimento disponíveis para a crítica e solução de problemas mediatizada por consultas à sociedade;

- Formar o gestor para ser um "tradutor cultural", capaz de compreender diferentes funcionamentos e lógicas e dialogar com as múltiplas identidades societárias, com atenção especial às questões de raça e de gênero;

- A reflexão dos servidores públicos sobre suas próprias práticas, buscando inserir, apesar dos constrangimentos conjunturais ou estruturais, os elementos da criatividade, do empoderamento da comunidade e do diálogo político em suas rotinas;

- Compreender as relações intrínsecas entre política, desenvolvimento e mudança social para dialogar e agir de forma cooperativa, sempre que possível;

- Buscar novas formas de articulação das políticas descentralizadas, criando capacidade para a gestão de múltiplas e diferentes redes, e para a coordenação transversal de programas no âmbito da Federação integrando e fortalecendo o fluxo de informações, propostas e soluções, características da sociedade-rede; 
- Incentivar a participação de atores locais e setoriais na esfera pública, estimular a conexão horizontal entre organizações públicas, privadas e comunidades, democratizando procedimentos e processos decisórios, liberando potencial político e empreendedor dos atores, apontando para diferentes arranjos e equilíbrio entre Estado, setor privado e terceiro setor.

Os dois exemplos ilustrativos apresentados anteriormente são característicos de um campo, segundo os padrões de Guerreiro Ramos (I965), que falha ao buscar o saber engajado, uma postura que valorize as ações práticas, que posicione o pesquisador em convergência com a participação ativa no processo societário e que traga maior compreensão da sociedade em que estão inseridos os pesquisadores. Nesse sentido, apesar de mostrarmos apenas dois exemplos, parece-nos bastante conveniente direcionar a construção do entendimento da administração pública nacional por vias de um saber engajado em responder, de modo criativo, singular, autêntico e interferente, aos problemas viventes do contexto da existencialidade do pesquisador, isto é, os problemas locais. A não preocupação e o entendimento das raízes/concepções dos fatos histórico-sociais e políticos do Brasil, acompanhados pela introdução in natura de teorias e ideais administrativos, podem tornar-se questões prejudiciais para a construção de um campo autêntico da administração pública nacional. Além disso, podem diminuir a capacidade de os pesquisadores darem respostas concretas e diretas aos problemas imediatos da sociedade local. Cabe, portanto, o desenvolvimento de conhecimentos e saberes locais introduzidos nas práticas administrativas das organizações públicas com intenção de aprimoramento dessas práticas e construção de preceitos que se encaixem plenamente em suas próprias realidades.

Como aponta Guerreiro Ramos (I965), a personalidade histórica de uma nação é constituída com base no entendimento concreto dos fatos que a determinam. Assim, parece-nos pertinente alegar que a administração pública nacional não pode ignorar ensaios que ajudaram a compreendê-la: os europeus que fundaram o Brasil; os povos que foram encontrados aqui; os escravos importados e seu trabalho; o tipo de sociedade que se organizou nos séculos de formação; a natureza da independência que separou o Brasil de Portugal; o funcionamento do regime estabelecido pela independência; o insulamento social de raças e gênero; o funcionamento da oligarquia republicana; a natureza da burguesia que domina o país; o imigrante que ajudou a tecer nossa cultura, economia e sociedade (Candido, 20I3). Nomes, portanto, que tentaram demarcar esses conhecimentos nacionais como Sérgio Buarque de Holanda, Manuela Carneiro da Cunha, Joaquim Nabuco, Kátia de Queirós Mattoso, Maurício Goulart, Gilberto Freire, 
Caio Prado Junior, Oliveira Lima, Manuel Bonfim, Oliveira Viana, Alcântara Machado, Fernando de Azevedo, Nestor Duarte, Raimundo Faoro, Celso Furtado, Fernando Novais, José Murilo de Carvalho e Evaldo Cabral de Melo poderiam ser dimensionados mais detalhadamente nos estudos da administração pública. Assim, aspirar à história brasileira significa aspirar à personalização, ao destino próprio e à construção autêntica do campo da administração pública nacional.

Pensarmos em uma administração pública nos moldes societais (De Paula, 2005), como parecem assinalar as necessidades participativas e inclusivas presentes no Brasil nos últimos anos, é também atentar-se à exaltação de premissas culturais e de raízes sócio-históricas do Brasil. O atendimento de anseios que viabilizem a participação popular na coprodução e cogestão de políticas e a ênfase em iniciativas locais de organização e gestão pública dificilmente serão enxergados na ausência de um método de análise dos fatos sociais dotado de valor pragmático e que reconheça, no interior da sociedade brasileira, a força central para perseguição das pretensões de desenvolvimento nacional. Na valorização da história como método, a administração pública nacional poderia pensar em novos arranjos institucionais, novos projetos políticos nacionais, novas relações entre Estado e sociedade que dessem conta, de forma bastante particular, da compreensão sistemática da administração pública nacional.

De modo parcialmente imbricado na reflexão sobre método histórico, buscaremos desenvolver a ideia de homem parentético como uma segunda esfera da proposta de redução sociológica de Guerreiro Ramos capaz de construir, mesmo que de modo parcial, uma resposta à seguinte indagação: "O que precisamos (re)conhecer para que o campo da administração pública nacional seja mais responsivo, correspondendo melhor aos anseios públicos locais?”.

Para Guerreiro Ramos (I98I), um dos principais pontos a serem reconhecidos no campo da teoria das organizações é a imperativa ascensão de uma abordagem substantiva das organizações. Em seus escritos, são percebidas as críticas, quase que constantes, aos ideais da administração científica desenvolvidas por Taylor e por seu operacionalista Herbert Simon, sobretudo quanto ao caráter associativo direcionado para atender a anseios mercadológicos e quanto à primazia da racionalidade instrumental, seja ela ilimitada ou limitada. Para Guerreiro Ramos (I98I), problemas sociais da modernidade como a insegurança psicológica, a degradação da qualidade de vida, a poluição e a exaustão dos recursos naturais do planeta demonstram a inconstância e a impossibilidade de manutenção e legitimidade de organizações e modelos sociais inscritos sobre as bases da racionalidade instrumental. Para tanto, o autor sugere a reformulação da teoria das organizações a partir de entendimentos epistemológicos dos quais o homem carece em diferentes cenários sociais, uma vez que é constituído por diferentes 
tipos de necessidades; o sistema de mercado só atende a um número baixo de necessidades humanas, e, se o homem se direcionar exclusivamente para o sistema de mercado, tenderá a agir como um ser com desempenho consistente, permeado por regras operacionais, instrumentais e exclusivo comportamento administrativo. Existem diferentes categorias de tempo e de espaço vital que são contempladas, em sua totalidade, somente pela existência de diferentes cenários organizacionais; sistemas cognitivos se modificam à medida que os cenários organizacionais se transformam. As regras de cognição referentes ao comportamento administrativo são apenas um caso particular; cenários sociais distintos requerem enclaves e vínculos distintos, e tais vínculos são pontos centrais de interesse da racionalidade substantiva.

O modelo parentético guerreiriano mostra-nos, portanto, uma nova perspectiva de pensar a administração pública nacional, em que a autorrealização, a procura pela interação social primária e as responsabilidades e satisfações sociais formem elementos basilares de um modelo responsivo de administração pública. Talvez as características de racionalidade substantiva sejam um dos fatores que levaram a nova administração pública (NAP) a não imperar solitária por muito tempo no Brasil. As características da NAP, embora primassem pela produtividade, redução de custos, melhoria da performance do setor público (Abrucio, I997), não conseguiram ampliar espaços de participação social; inclusive, em algumas análises, esses espaços foram substituídos por tomadas de decisões que partiam diretamente das instâncias superiores do Executivo nacional, a partir do instrumento legal de medida provisória (Diniz, I998). Mobilizações recentes que ocorreram no Brasil demonstram, entre outras necessidades, a ambição de parte da sociedade por modelos político-institucionais mais representativos questionando, inclusive, o formato da democracia representativa brasileira e a necessidade de uma reforma política no Estado. Formas mais democráticas de participação, portanto, tenderiam a incorporar e discutir o significado de práticas políticas participativas, a ampliação da gramática social e a inclusão de novos atores/temas nas políticas (Santos, 2002), por meio de exercícios substantivos de racionalidade que possibilitariam aos cidadãos se transformar em atores políticos e sociais.

Reconhecer a atitude parentética e, em especial, a racionalidade substantiva como uma maneira de tornar o campo mais responsivo aos anseios públicos locais é também possibilitar, além de uma democracia mais participativa, um sistema "paraeconômico" de governo capaz de formular e implementar políticas distributivas que permitam a potencialização das próprias atividades substantivas dos indivíduos. Tal sistema de governo, nos padrões de Guerreiro Ramos (I98I), poderia alocar mão de obra e recursos não exclusivamente em economias direcionadas para o mercado - produção, atividade remunerada e consumo -, 
mas também em isonomias e fenonomias ${ }^{\mathrm{I}}$ que, em grande maioria, são resultantes de pequenas atividades locais não remuneradas. Assim, o sistema paraeconômico de alocação de recursos e mão de obra ampliaria a gama de atividades humanas apreciadas com tais recursos, tendo grande possibilidade de incluir atividades substantivas, como: unidades domésticas; atividades artísticas, culturais e sociais não remuneradas; pequenas unidades rurais de produção e consumo próprio; atividades socioeconômicas, do terceiro setor, entre outras. A proposta é igualar as atividades isonômicas e fenonômicas às atividades econômicas de mercado em termos de importância na agenda de distribuição de recursos governamentais, denotando uma sociedade multicêntrica.

A atitude parentética pode apontar, ainda, na direção de um entendimento diferenciado sobre o processo de modernização das sociedades em desenvolvimento (Guerreiro Ramos, 2009) para, no caso deste trabalho, tornar o campo da administração pública mais responsivo e polido aos anseios públicos locais. O sociólogo, ao relatar a teoria $\mathrm{P}$, descreve o imperativo de as sociedades em desenvolvimento - no caso, o Brasil - buscarem seu próprio mecanismo e processo de modernização, uma vez que a implementação desse processo em um país não pode ser encontrada de antemão em outros países, isto é, não deve existir um tipo ideal de modernização, mas, sim, nações com possibilidades próprias de modernização. Em uma sociedade com presença de indivíduos parentéticos, portanto, a compreensão do processo de modernização poderia ser circunscrita sobre as bases da dialética da participação, em que todo o conhecimento teórico produzido estaria ligado a certa prática local para que não haja desequilíbrios entre os anseios do povo e a estrutura do sistema produtivo, tampouco relações assimétricas de dominação entre nações. Assim, a perspectiva parentética do cidadão o torna um "ser do mundo" capaz de interpretar, de modo crítico, a realidade nacional e ajudar na construção do processo de desenvolvimento do país.

\section{CONSIDERAÇÕES FINAIS}

Retomarmos o conceito de redução sociológica de Guerreiro Ramos em suas duas vertentes - método histórico e atitude parentética - teve o objetivo de colaborar na inserção desse conceito como tema de pesquisa para o campo

\footnotetext{
Um sistema isonômico é a representação de uma sociedade em que todos os indivíduos são iguais. Tem, especialmente, a proposta de permitir a atualização de seus membros, o sentimento de gratificação às pessoas; atividades realizadas pela vocação e não emprego; formas de tomada de decisão abrangentes; e relações interpessoais primárias entre os membros. Um sistema fenonômico tem as mesmas propostas do primeiro, com a diferenciação de ser coordenado por uma pessoa ou um grupo de pessoas (Guerreiro Ramos, I98I).
} 
da administração pública no Brasil. Muito embora a proposta guerreiriana não tenha sido esgotada nem revisitada em sua totalidade, dada a necessidade de atender à finalidade proposta no trabalho, os pontos escolhidos buscaram contribuir de duas formas principais para o campo da administração pública no Brasil: reavivar a necessidade de os pesquisadores brasileiros utilizarem conhecimento e produções científicas estrangeiras de maneira subsidiária, uma vez que há intenção primeira em atender às necessidades de uma realidade que, em muitos pontos, se apresenta de modo distinto das realidades em que as teorias/modelos surgiram; e fomentar a visão parentético-substantiva dos indivíduos para a construção de modelos de organização que, embora não excluam, façam com que modelos econômicos organizacionais dividam espaços com modelos mais voltados a garantir qualidade de vida, autorrealização, interação social primária, satisfações sociais e participação na produção de bens públicos.

Essas duas formas de contribuir para o campo da administração pública no Brasil, embasadas nos ideais de redução sociológica, estiveram estreitamente relacionadas com duas perguntas: "De que modo podemos desenvolver um entendimento mais sistemático da administração pública nacional?” e "O que precisamos (re)conhecer para que o campo da administração pública nacional seja mais responsivo, correspondendo melhor aos anseios públicos locais?". Obviamente, tais perguntas não conseguem sozinhas dar conta da complexidade do campo da administração pública no Brasil, mas, somente, colaboram para apontar um caminho mais participativo e de ampliação do conceito de "público". Diante disso, perguntas devem ser feitas e refeitas para a constante atualização e atendimento das necessidades humanas e sociais locais. Complementarmente, as respostas podem e devem ser elaboradas a partir de outras perspectivas teóricas, metodológicas, epistemológicas e até mesmo ontológicas, que não só a perspectiva de Alberto Guerreiro Ramos. Entretanto, tais perguntas e suas respostas não podem deixar em segundo plano a maneira como as organizações públicas se organizam para tornarem-se mais públicas, mais democráticas e mais capazes de expressar os valores de nossa sociedade.

Por fim, sugestões para futuras pesquisas parecem apontar para os seguintes temas: I. determinação dos requisitos estruturais e da ação humana que podem contribuir para o aumento da participação social deliberativa na coprodução de políticas e gestão públicas; 2 . estudos de caso mais profundos e constantes que permitam sedimentar o conhecimento sobre modelos e institutos de participação como: ouvidorias, fóruns, conselhos gestores, orçamento participativo, plataformas de acesso a informações públicas, entre outros; 3. novos formatos para a proposta de desenvolvimento, buscando realçar modelos advindos do terceiro setor, da economia solidária e de organizações familiares; 4 . formas cooperativas 
de gestão que buscam resolver conflitos de interesses no uso de bens comuns, com base na confiança e cooperação entre os atores; 5 . inserir nos cursos de administração, de modo mais lúcido e constante, o aprofundamento de literaturas nacionais que buscam e buscaram pensar em tipos organizacionais que privilegiam as relações e as necessidades humanas, tais como: Maurício Tragtenberg, Fernando Claudio Prestes Mota, Alberto Guerreiro Ramos, Maria Ceci Misocsky, José Henrique de Faria, Ana Paula Paes de Paula, entre outros.

\section{ALBERTO GUERREIRO RAMOS: SOCIOLOGICAL REDUCTION CONTRIBUTIONS TO THE SCIENTIFIC FIELD OF PUBLIC ADMINISTRATION IN BRAZIL}

\section{ABSTRACT}

The theoretical assay presents the proposal of Alberto Guerreiro Ramos on sociological reduction in the dimension of historical method and parenthetical position as suggested theme to study of scientific field of public administration in Brazil. We seek to dialogue with two questions: "How can we develop a more systematic understanding of national public administration?" and "What we need to (re)meet in order for the national field of public administration become more responsive, better corresponding to local public anxieties?". Based on Guerreiro Ramos, we suggested that the field uses the meth the methodological use of history studies; and parenthetical-substantive action. The first concerns to the critical assimilation of foreign intellectual that would allow one communitu no to be restrict to other communities experiences to achieve their own historic projects. The second is related to a lucid and active positioning of humans in relation to the factors that influence them, allowing an active set of those in society and especially in economic organizations. Reviving the need of Brazilian researchers use of scientific knowledge and foreign productions in a subsidiary way, once there is an intention of meeting the needs of a reality that, in many points, is presented differently from the realities in which the theories/models have emerged; foster parenthetical-substantive conception of individuals to build models of organization which, althought not excluding, make the organizational economic models to divide spaces with more models designed to ensure the quality of life, self-actualization, the primary social interaction, social satisfactions and participation in the production of public goods. 


\section{KEYWORDS}

Guerreiro Ramos. Sociological reduction. Scientific field. Public administration. Brazil.

\section{ALBERTO GUERREIRO RAMOS: CONTRIBUCIONES \\ DE LA REDUCCIÓN SOCIOLÓGICA AL CAMPO CIENTÍFICO DE LA ADMINISTRACIÓN PÚBLICA EN BRASIL}

\section{RESUMEN}

El ensayo teórico presenta la proposición de Alberto Guerreiro Ramos acerca de reducción sociológica, en la dimensión del método histórico y actitud parentética, como sugerencia en estudios acerca del campo científico de la administración pública en Brasil. Buscamos el diálogo con dos preguntas: “¿Cómo se puede desarrollar una comprensión más sistemática de la administración pública nacional?” y “¿Qué hay que (re)conocer para que el campo nacional de la administración pública sea más responsable, correspondiendo mejor a los deseos públicos locales?". Siguiendo Guerreiro Ramos, sugerimos que el campo de estudio haga uso metodológico de la historia y de la acción parentética-sustantiva. La primera se refiere a la asimilación crítica de la producción intelectual extranjera que permitiría a una comunidad no servirse solamente de experiencias de otras comunidades en la realización de su proyecto histórico. El segundo está relacionado a un posicionamiento lúcido y activo de los seres humanos en relación con los factores que influyen en ellos, lo que les permite un ajuste activo en la sociedad y sobretodo en las organizaciones económicas. Reviviendo la necesidad de que los investigadores brasileños utilicen los conocimientos científicos y las producciones extranjeras de manera subsidiaria, ya que se debe de satisfacer las necesidades de una realidad que, en muchos aspectos, se presenta de manera diferente de la realidad en la cual tales teorías/modelos han surgido; promover la concepción parentética-sustantiva en los individuos para la construcción de modelos de organización que, sin excluir los modelos económicos, hace con que estos dividan los espacios con más modelos diseñados para garantizar la calidad de vida, la autorrealización, la interacción social primaria, la satisfacción social y la participación en la producción de bienes públicos; son estos las sugerencias del trabajo. 


\section{PALABRAS CLAVE}

Guerreiro Ramos. Reducción sociológica. Campo científico. Administración pública. Brasil.

\section{REFERÊTCIAS}

Abrucio, L. F. (1997). O impacto do modelo gerencial na administração pública: um breve estudo sobre a experiência internacional recente. Cadernos Enap, Io, 52.

Azevêdo, A. (2006). A sociologia antropocêntrica de Alberto Guerreiro Ramos. Tese de doutorado, Universidade Federal de Santa Catarina, Florianópolis, SC, Brasil.

Bogason, P., \& Brans, M. (2008). Training and teaching: making public administration teaching and theory relevant. European consortium for Political Research, 7, 84-97.

Bourdieu, P. (2004). Usos sociais da ciência. São Paulo: Editora Unesp.

Candido, A. (2013). Antonio Candido indica io livros para conhecer o Brasil. Entrevista concedida à Editora Boitempo. Recuperado em Io novembro, 20Io, de http://blogdaboitempo.com. br/2013/05/I7/antonio-candido-indica-Io-livros-para-conhecer-o-brasil/.

Carvalho, J. M. D. (I997). Mandonismo, coronelismo, clientelismo: uma discussão conceitual. Dados, $40(2)$.

De Paula, A. P. P. (2005). Por uma nova gestão pública: limites e potencialidades da experiência contemporânea. São Paulo: FGV.

Diniz, E. (1998). Uma perspectiva analítica para a reforma do Estado. Lua Nova, 45, 29-48.

Fadul, É. M. C., \& Silva, M. D. A. M. A. (2009). Disciplinary limits and possibilities of public administration and organizational studies. Revista de Administração Contemporânea, 13(3), 35I-365. Faoro, R. (200I). Os donos do poder. Rio de Janeiro: Globo.

Ferrarezi, E., \& Silva, A. C. Z. da (2OI4). Formação de carreiras para a gestão pública contemporânea: o caso dos especialistas em políticas públicas e gestão governamental. Revista do Serviço Público, 57(I), 63-86.

Guerreiro Ramos, A. (I939). Introdução à cultura (ensaios). Rio de Janeiro: Cruzada da Boa Imprensa. Guerreiro Ramos, A. (I957). Introdução crítica à sociologia brasileira. Rio de Janeiro: Andes.

Guerreiro Ramos, A. (1965). A redução sociológica: introdução ao estudo da razão sociológica. Rio de Janeiro: Coleção Tempo Novo.

Guerreiro Ramos, A. (1970). A parenthetical trip (2) - man invents himself or toward a theory of the parenthetical encounter [Mimeo.]. Los Angeles, CA.

Guerreiro Ramos, A. (I972). Models of man and administrative theory. Public Administration Review, 32(3), 24I.

Guerreiro Ramos, A. (198I). A nova ciência das organizações: uma reconceitualização da riqueza das nações. Rio de Janeiro: Fundação Getulio Vargas.

Guerreiro Ramos, A. (I996). A redução sociológica. Rio de Janeiro: UFRJ.

Guerreiro Ramos, A. (2009). A modernização em nova perspectiva: em busca do modelo de possibilidades. In F. Heidemann \& J. F. Salm. Políticas públicas e desenvolvimento: bases epistemológicas e modelos de análise. Brasília: Editora UnB. 
Keinert, T. M. M. (I998). Do aparelho estatal ao interesse público: crise e mudança de paradigmas na produção técnico-científica em administração pública no Brasil (1937-1997): análise de conteúdo dos artigos publicados na Revista do Serviço Público (1937-...) e Revista de Administração Pública (1967-...). Tese de doutorado, Escola de Administração de Empresas de São Paulo, São Paulo, SP, Brasil.

Kettl, D. F. (2000). Public administration at the millennium: the state of the field. Journal of Public Administration Research and Theory, 10(I), 7-34.

Machado-da-Silva, C., Amboni, N., \& Cunha, V. (1989). Produção acadêmica em administração pública: período I983/88. Encontro da Associação Nacional de Programas de Pós-Graduação em Administração, Belo Horizonte, MG, Brasil, I3.

Orozco, O. G. (2009). La formulación de princípios en la administración pública. Convergencia: Revista de Ciencias Sociales, 16(49), I5-35.

Ortiz, R. (Org.) (1983). Pierre Bourdieu: sociologia. São Paulo: Ática.

Pacheco, R. S. (2003). Administração pública nas revistas especializadas: Brasil, I995-2002. Revista de Administração de Empresas, 43(4), 63-7I.

Peci, A., Ribeiro, A. J. G., Rodrigues, F. B. S., \& Fornazin, M. (20II). Paradigmas orientadores da pesquisa em administração pública no contexto brasileiro. Encontro Anual da Associação dos Programas de Pós-Graduação em Administração, Rio de Janeiro, RJ, Brasil, 35.

Raadschelders, J. C., \& Lee, K. H. (2OII). Trends in the study of public administration: empirical and qualitative observations from public administration review, 2000-2009. Public Administration Review, 71(I), I9-33.

Santos, B. D. S. (2002). Democratizar a democracia: os caminhos da democracia participativa. Rio de Janeiro: Civilização Brasileira.

Serva, M. (1997). A racionalidade substantiva demonstrada na prática administrativa. Revista de Administração de Empresas, 37(2), I8-30.

Weible, C. M., Sabatier, P. A., \& McQueen, K. (2009). Themes and variations: taking stock of the advocacy coalition framework. Policy Studies Journal, 37(I), I2I-I40. 